\title{
A comparison of symptoms and intra-arterial ambulatory blood pressure during long term dual chamber atrioventricular synchronous (DDD) and ventricular demand (VVI) pacing
}

\author{
N A BOON, * A J FREW, $\dagger$ J A JOHNSTON, S M COBBE $\ddagger$ \\ From the Department of Cardiovascular Medicine, John Radcliffe Hospital, Headington, Oxford
}

SUMMARY Fifteen patients with dual chamber pacemakers implanted for atrioventricular block (11) or sinoatrial disease (4) completed a single blind within-patient comparison of symptoms and 24 hour intra-arterial blood pressure during long term atrioventricular synchronous (DDD) pacing and long term ventricular demand (VVI) pacing. The patients reported significantly less breathlessness, fatigue, and dizziness and a significantly greater sense of general well-being during DDD pacing than during VVI pacing. Twelve of the fifteen patients expressed a strong preference for DDD pacing. Systolic blood pressure tended to be lower and was significantly more variable during VVI pacing than during DDD pacing (mean (SD) daytime systolic blood pressure 132.4 (17.1) and 140.4 (13.1) $\mathrm{mm} \mathrm{Hg}$ respectively). Accordingly, episodes of hypotension were more common during VVI pacing, which may partly explain why the patients reported more symptoms during this mode of pacing.

Dual chamber or atrioventricular synchronous (DDD) pacing has several theoretical advantages over ventricular demand (VVI) pacing. ${ }^{1}$ These include the ability of DDD pacing to maintain the normal activation sequence of atrial and ventricular systole and to provide a degree of rate responsiveness.

Several groups have shown that in patients with atrioventricular conduction block, long term atrioventricular synchronous pacing produces better haemodynamic function, ${ }^{2}$ a greater effort tolerance, ${ }^{2-4}$ and fewer symptoms ${ }^{34}$ than long term ventricular demand pacing. There is also evidence that patients who require pacing for sinoatrial disease

Requests for reprints to Dr N A Boon, Department of Cardiology, Edinburgh Royal Infirmary, Lauriston Place, Edinburgh EH3 9YW.

Present addresses: ${ }^{\star}$ Department of Cardiology, Edinburgh Royal Infirmary, Edinburgh; †Department of Allergy and Clinical Immunology, Cardiothoracic Institute, Brompton Hospital, Fulham Road, London SW3 6HP; 抱artment of Medical Cardiology, Glasgow Royal Infirmary, Glasgow.

Accepted for publication 17 February 1987 experience fewer symptoms during atrioventricular sequential pacing than during ventricular demand pacing. ${ }^{5}$ Because most patients receiving pacemakers are elderly, the maximum effort tolerance achieved during a treadmill test is probably of little relevance to their daily life. However, any improvement in symptoms such as dizziness, shortness of breath, or in general well-being is clearly worth while.

In some patients ventricular demand (VVI) pacing can induce episodes of pronounced symptomatic hypotension, ${ }^{67}$ a condition often known as the pacemaker syndrome. Atrioventricular synchronous (DDD) pacing may help to prevent such attacks, at least in patients with the carotid sinus syndrome. ${ }^{8}$ Some of the symptoms reported during ventricular demand pacing, particularly minor dizzy spells, may be due to less florid forms of this phenomenon. We have, therefore, compared symptoms and intra-arterial 24 hour ambulatory blood pressure in a group of unselected patients during long term dual chamber (DDD) and long term ventricular demand (VVI) pacing. Some of these data have been presented in preliminary form at the British Cardiac Society. ${ }^{9}$ 

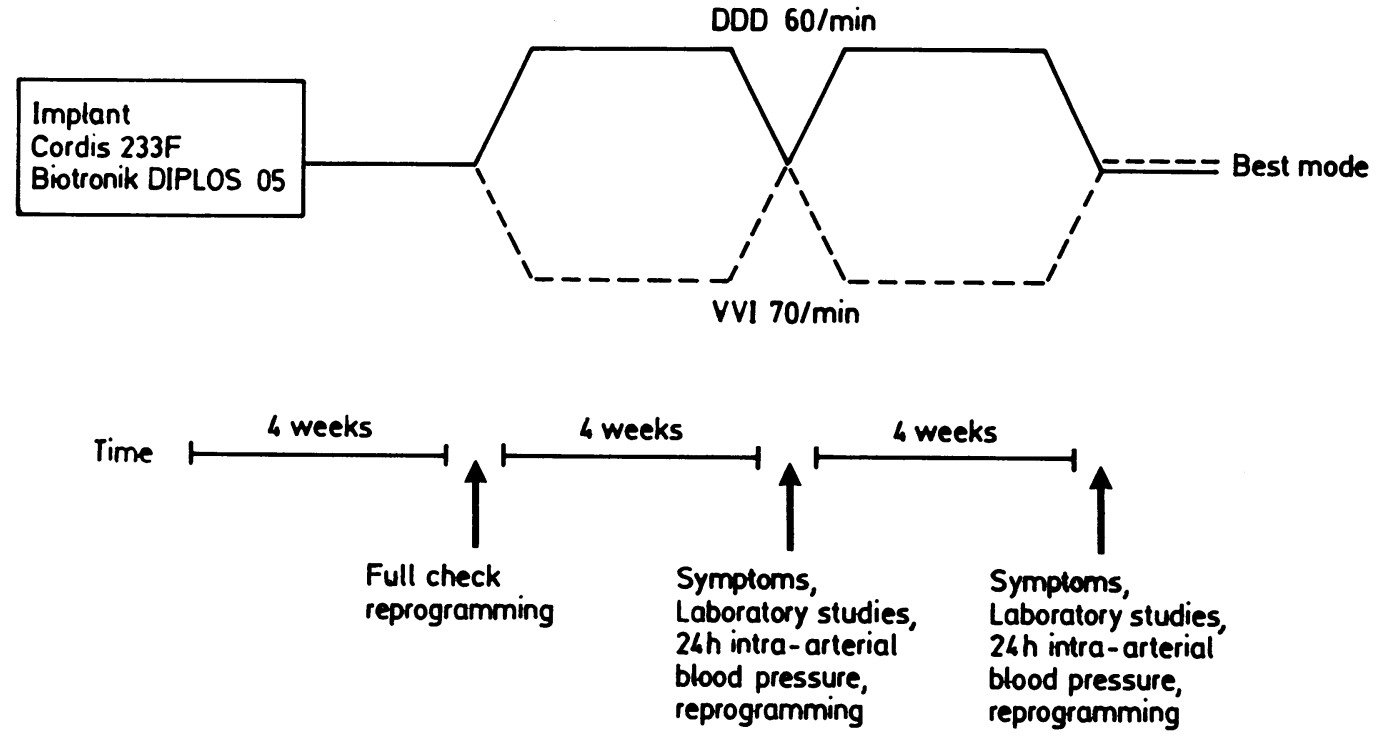

Fig 1 Design of the study.

\section{Patients and methods}

\section{PATIENT SELECTION}

Dual chamber pacemakers (Cordis $233 \mathrm{~F}$ or Biotronic Diplos 05) were implanted in a group of 18 patients chosen at random from those receiving pacemakers at the John Radcliffe Hospital during the period of the study. The indications for pacing were: complete heart block and syncope (6), complete heart block with presyncope or shortness of breath (3), asymptomatic complete heart block (1), left bundle branch block and syncope (1), sinoatrial disease with syncope (3), sinoatrial disease with presyncope (1). The only exclusion criteria were the presence of atrial fibrillation or angina on effort. Patients were invited to take part in the study when they came to the hospital for routine checks one month after implantation of the pacemaker. Informed written consent was obtained in every case and the study was approved by the Central Oxford Regional Ethics Committee.

\section{PROTOCOL}

Figure 1 shows the design of the study. After recruitment, patients were randomly allocated, single blind, to either VVI pacing at a rate of 70 or 72 per minute or DDD pacing with a back up rate of 60 per minute (the atrioventricular delay and atrial refractory period were selected by the cardiologist in charge of the case). After an equilibration period of at least four weeks each patient underwent a symptom assessment and a 24 hour ambulatory recording of the electrocardiogram and intra-arterial pressure. The pacemaker was then programmed to the opposite mode and the observations were repeated after a further equilibration period of at least four weeks. Several laboratory measurements were made immediately before each 24 hour blood pressure recording and these will be the subject of a separate report. At the end of the study the pacemaker was reprogrammed to the DDD mode unless the patient had expressed a strong preference for VVI pacing.

\section{DATA COLLECTION}

Symptom assessment

Shortness of breath, dizziness, fatigue, and general well-being were assessed at each visit on a $10 \mathrm{~cm}$ visual analogue scale. At the end of the study patients were asked to express a preference for one of the two forms of pacing.

\section{4 hour ambulatory blood pressure and electrocardiogram recording}

The Seldinger technique was used to place a Teflon cannula (internal diameter $1 \mathrm{~mm}$, Plastimed) in the brachial artery of the non-dominant arm. This was connected to a portable perfusion pump, transducer, and miniature analogue tape recorder (Oxford Medilog). ${ }^{10}$ The surface electrocardiogram and pacemaker spike were recorded on additional channels of the tape recorder.

Patients were asked to keep a diary of the day's events and were encouraged to remain as active as possible during the period of the recording. All but 
four patients returned to their homes for the duration of the recording; those who stayed in hospital remained ambulant during the day. In every case one of the investigators checked the apparatus carefully immediately before the patient retired to bed. Unfortunately, in three cases the cannula became partly or compietely blocked during the night; the nocturnal records for these patients were excluded from the final analysis.

\section{DATA ANALYSIS}

Beat to beat analyses of : ':e 24 hour blood pressure and electrocardiogram records were riade with an Eclipse S200 computer programmed to analyse the systolic blood pressure, diastolic blood pressure, arithmetic mean blood pressure, and $R R$ interval. Data collected while the patients were asleep were analysed separately from data collected while they were awake.

\section{STATISTICAL METHODS}

We used Student's paired $t$ test to compare differences in blood pressure and the Wilcoxon signed rank test for paired data to compare differences in all other variables.

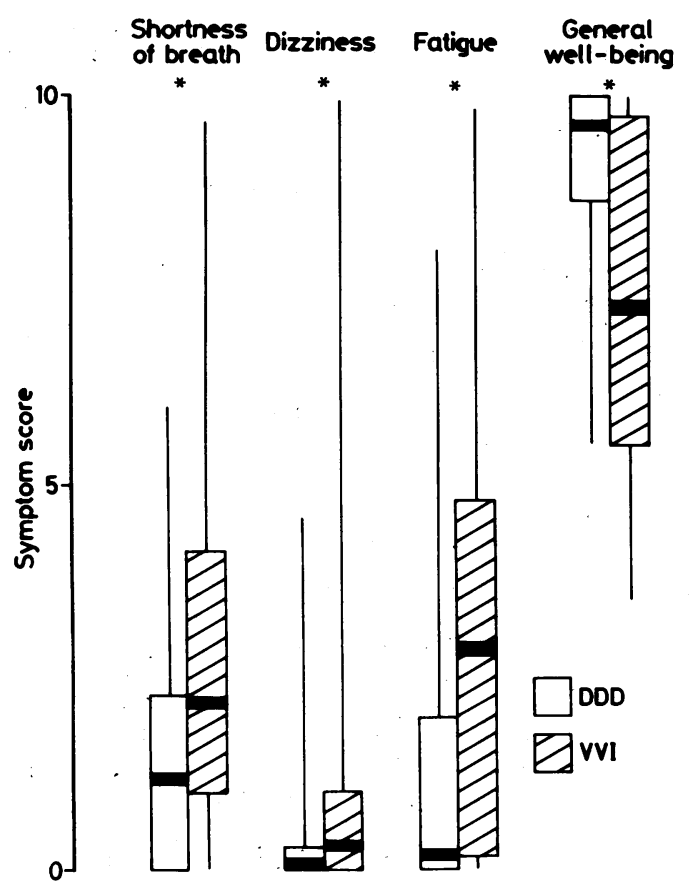

Fig 2 Symptom scores during DDD and VVI pacing. Data are presented as the median (bar), interquartile range (box), and full range of values. ${ }^{\star} p<0.05$ Wilcoxon signed rank test; $n=15$.

\section{Results}

PATIENT DETAILS

Eighteen patients entered the study but we withdrew three patients after they completed the first limb of the study. One of these three patients was withdrawn from the study because he was found to have a disseminated malignant tumour. Angina developed in the other two; in one this was associated with a change from DDD to VVI pacing and in the other it was associated with a change from VVI to DDD pacing.

Fifteen patients ( 13 men, 2 women) completed the study. Of these, seven were allocated to VVI pacing followed by DDD pacing and eight were allocated to DDD pacing followed by VVI pacing. The mean age of these patients was 69 years (range 54-81 years).

Two patients with sinoatrial disease and one patient with complete heart block had demonstrable ventriculoatrial conduction at the time of the pacemaker implant. A fourth patient, who was paced for sinoatrial disease, was shown to have intermittent ventriculoatrial conduction during the course of the

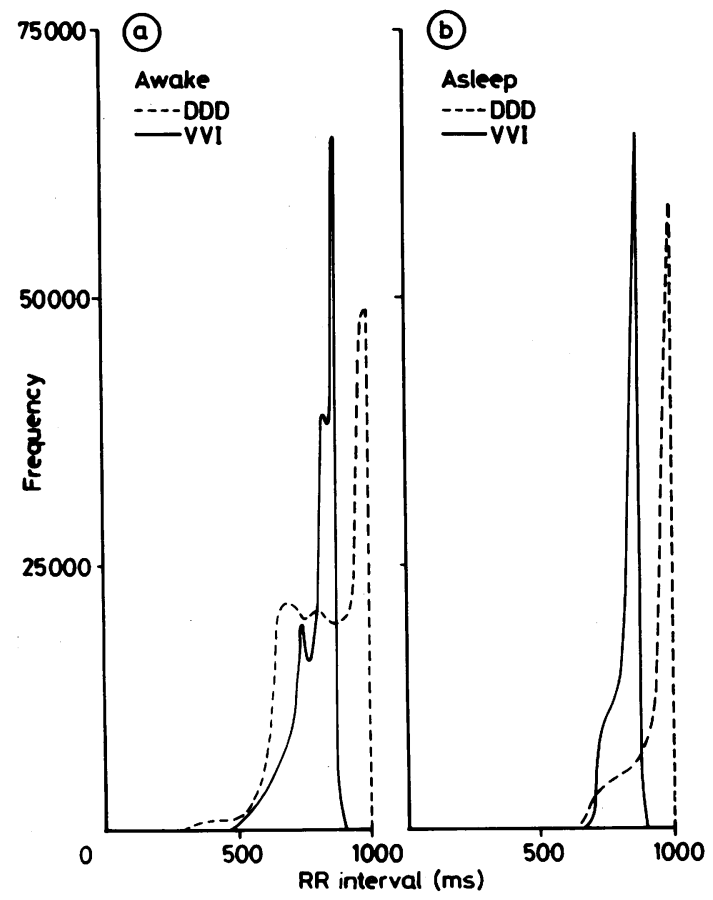

Fig.3. Distribution of the RR interval, defined to the nearest $8 \mathrm{~ms}$, during $D D D$ and VVI pacing during wakefulness $(n=15)$ and sleep $(n=12)$. The data are presented as $a$ frequency histogram that includes every recorded heart beat in every patient. 
Table Mean (SD) blood pressure while patients were awake or asleep

\begin{tabular}{lrr}
\hline & VVI pacing & DDD pacing \\
\hline Awake $(\mathrm{n}=15):$ & & \\
Systolic BP & $132.4(17.1)$ & $140.4^{\star}(13.1)$ \\
Mean BP & $94.2(14.4)$ & $97.9(9.9)$ \\
Diastolic BP & $74.4(13.1)$ & $74.7(10.3)$ \\
Asleep $(\mathrm{n}=12):$ & $118.2(17.7)$ & $119.5(14.9)$ \\
Systolic BP & $85.6(10.8)$ & $85.0(11.6)$ \\
Mean BP & $68.0(7.7)$ & $64.2(11.6)$ \\
Diastolic BP & &
\end{tabular}

${ }^{\star} \mathrm{p}<0.02$, Student's paired $t$ test. BP, blood pressure.

study. In the other eleven patients ventriculoatrial conduction was not seen.

\section{SYMPTOMS}

The patients, as a group, reported significantly less shortness of breath, dizziness, and fatigue during DDD pacing (fig 2). DDD pacing was also associated with a significantly greater sense of general well-being (fig 2). At the end of the study twelve patients expressed a strong preference for DDD pacing, two patients expressed no preference, and one patient expressed a strong preference for VVI pacing.

HEART RATE AND RHYTHM

Figure 3 shows the distribution of the RR interval (measured to the nearest $8 \mathrm{~ms}$ ) during VVI and DDD pacing while the patients were asleep and awake. The data are presented as a cumulative frequency histogram for all fifteen patients. During VVI pacing the pacing rate was either 70 or 72 per min whereas during DDD pacing the back up rate was 60 per min. The median values for the daytime RR intervals during DDD $(805 \mathrm{~ms})$ and VVI $(828 \mathrm{~ms})$ pacing were not significantly different. There was a much greater range of $R R$ interval during DDD pacing. At night the median RR interval was significantly longer during DDD (946 ms) pacing than during VVI $(844 \mathrm{~ms})$ pacing $(\mathrm{p}<0.01$, Wilcoxon signed rank test).

Analysis of individual records showed that during VVI pacing all but one patient experienced nearly continuous ventricular pacing. The remaining patient was in sinus rhythm for most of the time. Three other patients had episodes of sinus rhythm during the 24 hour period; a further three patients experienced quite frequent $(>1$ per $\mathrm{min}$ ) ventricular ectopic complexes and one patient had very frequent ( $>3$ per min) ventricular ectopic complexes. During DDD pacing two patients experienced short runs of pacemaker mediated tachycardia. The maximum tracking rate of the pacemaker, which ranged from 92 to 150 beats $/ \mathrm{min}(650-400 \mathrm{~ms} R R$ interval)

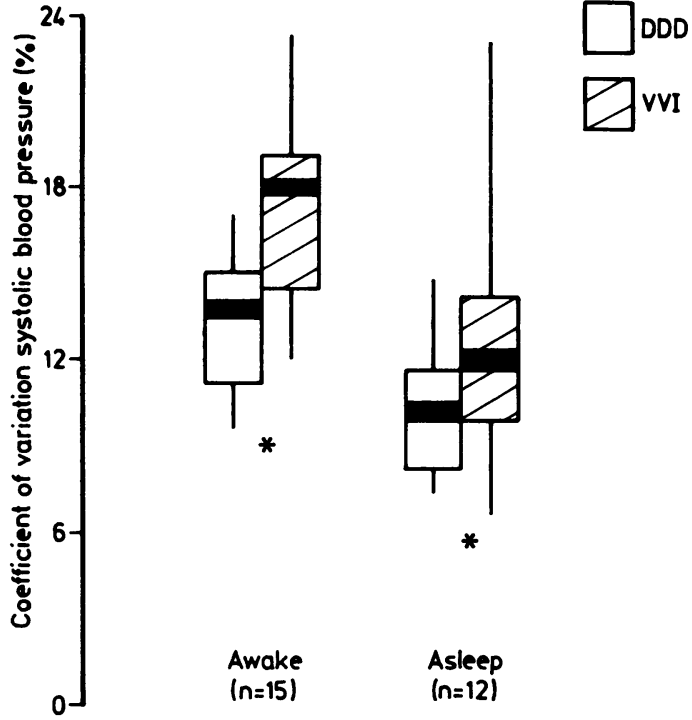

Fig 4 Coefficients of variation for systolic blood pressure during $D D D$ and VVI pacing during wakefulness $(n=15)$ and sleep $(n=12)$. The data are presented as the median (bar), interquartile range (box), and full range of values. ${ }^{\star_{p}}<0.01$ Wilcoxon signed rank test.

(median value 108 beats/min ( $550 \mathrm{~ms} R$ interval)), was achieved at least once during the 24 hours in six of the 15 patients.

\section{BLOOD PRESSURE}

The table gives the mean (SD) systolic, diastolic,

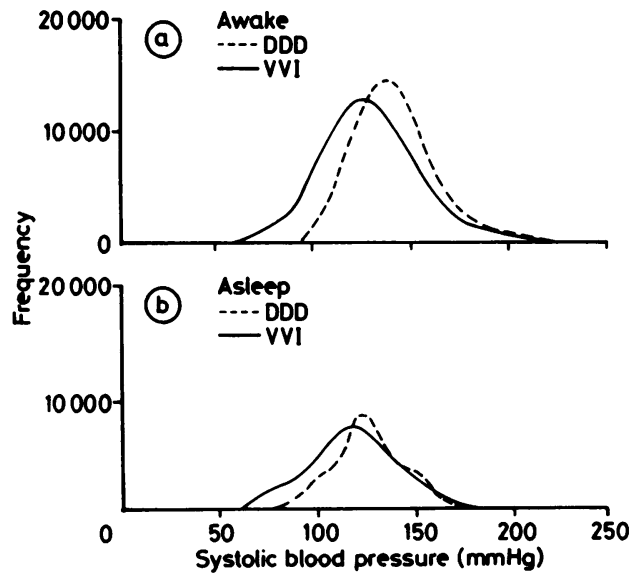

Fig 5 Distribution of the systolic blood pressure, measured to the nearest $\mathrm{mm} \mathrm{Hg}$, during $D D D$ and VVI pacing during wakefulness $(n=15)$ and sleep $(n=12)$. The data are presented as a frequency histogram that includes every recorded heart beat in every patient. 

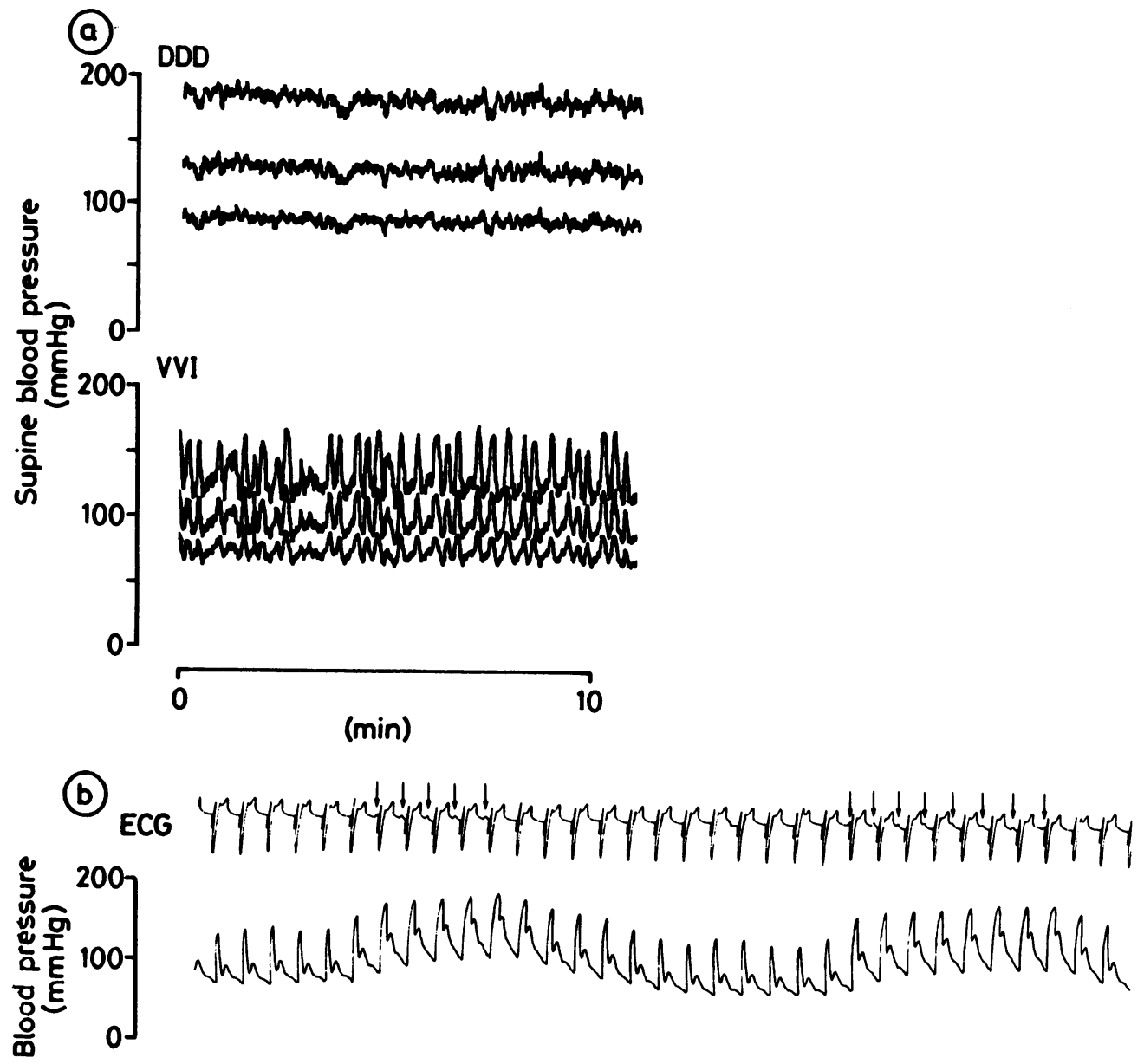

Fig 6 (a) Computer generated trend recording of systolic, arithmetic mean, and diastolic intra-arterial blood pressure during DDD and VVI pacing in the same patient lying supine at the same time of day. (b) Higher speed recording of the intra-arterial blood pressure during VVI pacing shown in (a) together with the electrocardiogram in which the $P$ waves are identified by arrows.

and arithmetic mean blood pressures during DDD and VVI pacing. Systolic blood pressure tended to be lower during VVI pacing and this difference was significant $(\mathrm{p}<0.02$, Student's paired $t$ test) for the period when the patients were awake.

\section{BLOOD PRESSURE VARIABILITY}

The coefficients of variation for systolic blood pressure during wakefulness and sleep were considerably greater during VVI pacing than during DDD pacing (fig 4). In every patient the difference favoured DDD pacing. The coefficients of variation for mean and diastolic blood pressures were also significantly greater during VVI pacing than during DDD pacing (data not shown).
Figure 5 shows the distribution of the systolic blood pressures (to the nearest $\mathrm{mm} \mathrm{Hg}$ ) during the two modes of pacing. The greater variability in systolic blood pressure during VVI pacing is evident. The data are presented as a frequency histogram of the systolic blood pressure for every heart beat in every patient. These curves clearly demonstrate that the mean systolic blood pressure was slightly lower during VVI pacing than during DDD pacing and that the range of systolic blood pressure was much greater during VVI pacing than during DDD pacing. Accordingly there were more episodes of systolic hypotension during VVI pacing. While very few heart beats produced a systolic blood pressure of $<100 \mathrm{~mm} \mathrm{Hg}$ during DDD pacing, approximately 
80000 heart beats produced a systolic blood pressure of $<100 \mathrm{~mm} \mathrm{Hg}$ during VVI pacing.

Figure 6 shows short recordings of the blood pressure during VVI and DDD pacing in the same patient under the same conditions. The greater blood pressure variability during VVI pacing is obvious and in this case can be clearly related to the presence of atrioventricular dissociation.

\section{Discussion}

This study has confirmed that most patients experience fewer symptoms during long term atrioventricular pacing than during long term ventricular demand pacing. ${ }^{3-5}$ This may be the result of several factors such as the absence of cannon waves, better haemodynamic function, and better control of blood pressure. The patients who took part in this study are representative of patients treated by permanent pacing at this centre. It therefore appears that DDD pacing may offer additional benefit to a wide group of patients.

Our findings demonstrate, beyond doubt, that long term DDD pacing gives better control of blood pressure with fewer episodes of hypotension than long term VVI pacing. Indeed, DDD pacing in our patients produced average values for intra-arterial ambulatory blood pressure and blood pressure variability that are very similar to those reported in a group of healthy elderly normotensive subjects. ${ }^{11}$ In contrast, VVI pacing was associated with a significantly lower and significantly more variable blood pressure and, therefore, with more frequent episodes of hypotension. It seems likely that some of the symptoms reported during the period of VVI pacing were caused by these episodes of hypotension. Certainly, at times the blood pressure fell below the likely lower limit of cerebral autoregulation. ${ }^{12}$ Unfortunately we do not know whether or not our patients' symptoms coincided with episodes of hypotension. This is partly because we asked our patients to report symptoms that had occurred in the month before the 24 hour blood pressure recording and partly because in most cases the symptoms experienced during VVI pacing were ill-defined and could not be timed accurately.

The pronounced increase in blood pressure variability seen during VVI pacing, compared with that seen during DDD pacing or in elderly normotensive subjects, ${ }^{11}$ is almost certainly caused by atrioventricular dissociation. Figure $6 \mathrm{~b}$ shows how changes in the relative timing of atrial and ventricular systole can produce profound changes in blood pressure. The fact that VVI pacing was associated with greater blood pressure variability than DDD pacing, even when patients were asleep and paced virtually continuously (fig 3 ), provides strong evidence that this difference is a function of atrioventricular dissociation rather than rate responsiveness. There may, therefore, be a similar increase in blood pressure variability in patients treated with rate-responsive VVI pacemakers.

This study provides further evidence that atrioventricular pacing is better than ventricular demand pacing and should be considered in all suitable patients.

\section{References}

1 Geddes JS. "Physiological" pacing. Br Heart J 1983;50:109-11.

2 Kruse I, Arnman K, Conradson TB, Ryden L. A comparison of the acute and long-term hemodynamic effects of ventricular inhibited and atrial synchronous ventricular inhibited pacing. Circulation 1982;65:846-55.

3 Perrins EJ, Morley CA, Chan SL, Sutton R. Randomised controlled trial of physiological and ventricular pacing. Br Heart J 1983;50:112-7.

4 Kristensson BE, Arnman K, Smedgard P, Ryden L. Physiological versus single rate ventricular pacing: a double blind cross-over study. PACE 1985;8:73-84.

5 Stone JM, Bhakta RD, Lutgen J. Dual chamber sequential pacing management of sinus node dysfunction: advantages over single chamber pacing. $\mathbf{A m}$ Heart J 1982;104:1319-27.

6 Alicandri C, Fouad FM, Tarazi RC, Castle L, Morant $V$. Three cases of hypotension and syncope with ventricular pacing. Possible role of atrial reflexes. $\mathrm{Am} \mathrm{J}$ Cardiol 1978;42:137-42.

7 Jones RI, Cashman PMM, Hornung RS, Prince H, Bassein L, Raftery EB. Ambulatory blood pressure and assessment of pacemaker function. Br Heart $\mathrm{J}$ 1986;55:462-8.

8 Morley CA, Perrins EJ, Grant P, Chan SL, McBrien DJ, Sutton R. Carotid sinus syncope treated by pacing. Analysis of persistent symptoms and role of atrioventricular sequential pacing. $\mathrm{Br}$ Heart $J$ 1982;47:411-8.

9 Boon NA, Frew AJ, Cobbe SM. An intra-patient comparison of ambulatory blood pressure during chronic DDD and VVI pacing [Abstract]. Br Heart $J$ 1986;55:508.

10 Littler WA, Honour AJ, Sleight P, Stott FD. Continuous recording of direct arterial pressure and electrocardiogram in unrestricted man. $\mathrm{Br} \mathrm{Med} J$ 1972;iii:76-8.

11 Rowlands DB, Stallard TJ, Littler WA. Continuous ambulatory monitoring of blood pressure and assessment of cardiovascular reflexes in the elderly hypertensive. J Hypertens 1984;2:615-22.

12 Strandgaard S, Olesen J, Skinhoj E, Lassen NA. Autoregulation of brain circulation in severe arterial hypertension. $\mathrm{Br}$ Med J 1973;i:507-10. 